\section{Ha fallecido hace algunos meses el Dr. Raúl Álvarez de Oro}

\section{Trascribimos carta homenaje de un distinguido discípulo suyo}

\section{El Doctor Raúl Álvarez de Oro}

A todos aquellos que fuimos sus discípulos en la disciplina de la Cirugía Torácica nos conmueve la noticia de la muerte de quien fue uno de nuestros maestros. A todos los cirujanos generales, muchos de los cuales son socios de la Sociedad de Cirujanos de Chile nos tocó en algún momento de la residencia rotar por el Hospital del Tórax. Para los cirujanos digestivos, que eran legos en esta disciplina, nos sorprendía aquello que siempre nos decía que entre la barriga y el cuello había un amplio campo en el cual pocos tenían verdadero oficio y que él nos demostraba tanto en las sesiones clínicas como en el quirófano y en la consulta externa. Gran conocedor de la anatomía, nos sorprendía muchas veces su elegancia en la disección así como todos los trucos y habilidades posibles para hacer una resección impecable, de manera tal que algunos lo seguimos hasta tomar esta suerte de alternativa al dedicarnos al proceloso camino de la cirugía pulmonar. Así nos quedamos en su servicio. Durante los años que estuvimos juntos, la cirugía cambió de tal forma que la eclosión de la imagenología moderna nos dejó muchas veces sin ningún argumento a favor de lo que en un principio era la cirugía de exploración; la aparición de técnicas complementarias que mostraban las evidencias de una cirugía mucho más exacta nos permitiría resecar solamente lo que nos aseguraba que era suficiente para curar, ayudado por las otras ramas de la oncología en el tórax. Así pasaron todos esos años, sin duda de evolución positiva para la especialidad; llegó el tiempo de su jubilación y, queriéndolo o no, había dejado ya una pléyade grande de discípulos diseminados por todos los hospitales chilenos especialmente en Santiago, Valparaíso, Concepción y Valdivia, los que sin duda nos superan en este momento a todos los que dentro del equipo del maestro contribuimos a formarlos. Siempre bromeábamos cuando le recordábamos que no era socio de la Sociedad de Cirujanos y nos respondía con su ya clásica pachorra argentina: - Y bueno, es que nadie tiene los puntos suficientes para revisarme un trabajo de ingreso... El maestro no está en la sociedad, es verdad, pero sí estamos todos los que fuimos de los suyos y creo que en este momento se apuntarán, seguros a este pequeño homenaje.

Descanse en paz.

Dr. Carlos Bidegain-Pavón, MSCCH. Girona, España. 15 de junio de 2013 